\title{
Research of Oroqen Dance Culture
}

\author{
Rui Zhang \\ School of Music \\ Heihe University \\ Heihe, China
}

\begin{abstract}
The thesis intends to analyze the development and heritage of the dance of Oroqen, a nation living in Heilongjiang River Basin based on the research on its origin, name, population distribution and dance styles so as to push the development of the Oroqen dance culture.
\end{abstract} culture

Keywords-Heilongjiang River Basin, oroqen; dance;

\section{INTRODUCTION}

Oroqen, one of the three minorities of Inner Mongolia, has its own language but no characters. It has drawn attentions from numerous domestic and foreign institutions to protect immaterial cultural heritage. Its population is mainly distributed in the area of the Great Khingan and the Lesser Khingan in Heilongjiang Province and Northeast of Inner Mongolia Autonomous Region, between $48-53^{\circ} \mathrm{N}$ and $122-131^{\circ}$ E. Earlier, they lived mainly by Safari. Now, they live mainly by farming with stronger awareness of environment. They used to hunt in the Great Khingan and the Lesser Khingan. On the vast and fertile land of Northeast China flows the Heilongjiang River and its origin, Erguna River, in the north. They are also the border between China and Russia. To the Songliao Plain in the south zigzags the Nen River. The Great Khingan slants across the Heilongjiang Province and Inner Mongolia Autonomous Region from Northeast to Southwest. The width is around 200-300 kilometers and the altitude is 1000-1400 meters. The thesis intends to research the culture and resource of Oroqen dance in Heilongjiang River Basin so as to push the heritage and development of the Oroqen dance under the background of multi-cultural integration and development.

\section{ORIGIN OF OROQEN}

The Northeast China where the Oroqen lives started political liens with central area of China since 11th century B.C.

\section{A. Origin of the Oroqen People}

There are two opinions that Oroqen is originated from the nation Sushen or Donghu. As one nation in ManchuTungusic Branch, Sushen has some ties with the Oroqen but

[Research Project]:

Key research project of Heihe University

Strategic research of the modern heritage of expressive art of Oroqen in Heilongjiang River Basin, Origin: planned project of philosophy and social science in Heilongjiang Province, Project Number: 15YSE11. it is not the direct ancestor of the Oroqen. According to the ancient historical recordings, the "Shiwei" people in Southern and Northern Dynasties have direct relationship with the Oroqen. "Shiwei" does not refer to a single nation, but all the nations in the north of Huji. "Shiwei" is divided into five tribes: "South Shiwei", "North Shiwei", "Bo Shiwei", "Shenmoheng Shiwei" and "Great Shiwei". They are different in productive and life styles. Probably, "Bo Shiwei" is the origin of the Oroqen.

One strong proof for this relationship is that both share a particular residence style. According to History of Northern Dynasties, "Bo Shiwei" has larger population than "North Shiwei"; their lifestyle is the same with "North Shiwei" except that they use birch bark for house. The difference of the residence styles between the two nations are indicated in the recording. "Bo Shiwei" adopts birch bark while "North Shiwei" lives in the holes.

\section{B. Name}

There are two opinions on the meaning of the Oroqen Some believe that "Oroqen" means the reindeer raiser. According to the relative recording, the Oroqen has ever raised reindeer. Later, they migrated to the South gradually. The reindeer lives on moss. However, the south bank of Heilongjiang River is not suitable for the reindeer. Thus, the Oroqen stopped raising the reindeer finally. According to some Oroqen scholars, the Oroqen did raise the reindeer before. The "Aorenqian" means the people raising reindeer. Others believe that "Oroqen" means the people on the mountain. They started to be called "Oroqen" since 1958. There are also a lot of Oroqen people in Russia. The Oroqen and Ewenki are all called "Aiwendei". The only difference is that the Oroqen raises the reindeer and the Ewenki rides on the horse.

\section{Population and Distribution}

Globally, the Oroqen people live in the Heilongjiang River basin and Sakhalin Island age after age. A few of them live in the area across Heilongjiang River in Mongolia. Some of them live in the area from the upstream of Jiya River to Vladivostok. There are also a few of them living in the Sakhalin Island.

In China, the Oroqen people are distributed in Inner Mongolia and Heilongjiang Province. Heihe and Yichun are in the area of Lesser Khingan Mountains. Inner Mongolia and Jiayin are in the area of the Greater Khingan Mountains. 
In Inner Mongolia, the Oroqen is mainly distributed in Oroqen Autonomous Banner and in Heilongjiang River area, the Oroqen is mainly distributed in Tahe, Huma, Xunke and Jiayin.

\section{CHARACTERISTICS OF OROQEN DANCE}

The Oroqen live by safari. They live and work in groups. They are simple, industrious and courageous. Their dance contains various scenes and plots in expressive style. The background music is lively in rhythm and melodious in tunes. They use their music and dance to eulogize the nature and love. They sing and dance to express their worship of the nature and beautiful expectations to the life.

\section{A. Dance Style}

There are five performance styles in Oroqen dance. The first is the Shaman dance of sacrifice and divination, the dance of witches. Beating the divine drums, the witches sing and dance. The rhythm of their movements gets faster and faster to hysteria. They rotate with the drum beat gradually quickening. The second is "Lv Ri Ge Ren", an integration of Oroqen folk music, poem and dance. The third is the entertainment dance, such as the Bear-Fighting Dance and Silkie Dance. The Bear-Fighting Dance should be performed by at least three people. Half-squatting with hands above the knees, the performers seems ready to fight with a bear. The performers dance in the rhythm of the sound like bear's fighting and snore. There are dragging steps and split steps. The performers step down with the down beat. The dancers go along the transverse line and a cross. The silkie dance stimulates the birds and beasts. It stimulates the silkie to express the happiness. The dance is performed by two or four dancers. With two arms on the hips, the dancers jump in a formation like silkies with music and cries. The forth is the dance during clan council, which is called "Yi He Na Ren". The fifth is the labor dance called "Hong Pu Nen" which means picking the hill haw. It is performed in groups of two people. Two dancers in the group rotate face to face with the musical rhythm. When one steps forward, the other one steps backward. The dancers clap after each rotation. The movements resemble picking hill haw.

\section{B. Dance Style}

Oroqen dance is vigorous and forcible, gentle and graceful, slow and generous, lithe and graceful.

\section{Current Situation of Oroqen Dance Culture}

Currently, Oroqen dance in Heilongjiang River Basin is facing a severe situation now. Its heritage and development is in no way optimistic. It is presented in the following two aspects:

\section{A. Smaller Communication Scope}

Oroqen dance culture is developing in a narrowing scope and with many limitations, facing the shock and challenge from modern economy. There are few young people intending to inherit and develop Oroqen dance. Some special
Oroqen dances are sinking to oblivion in the wave of historical development and out of our view.

\section{B. Less Spreader}

The spreaders of Oroqen dances teach spontaneously out of their enthusiasm and sense of mission. So, we can see that the dance teaching is lack of supports from society and government.

\section{Measures on DeVElopment of Orogen Dance}

For the problems mentioned above, the solutions should be based on the construction of cultural institution systems and the leading of government. We should cultivate the awareness to inherit immaterial cultural heritage and popularize the dance courses so as to create a good environment for the development of dance culture. The measures are as follows:

\section{A. Construction of Cultural Institutions and Leading of the Government}

With the development of market economic system and upturn of living standards, local government departments start to put more emphasis on the heritage and development of traditional artistic culture. Nowadays, it has become a key standard of governance capability whether the government departments and institutions can take advantage of culture and art as a special resource for local economic development and modernization construction. As for the Heilongjiang River Basin, the government departments should use local dance culture as a trump card to organize various cultural, artistic and traveling festivals. In these special festivals, we can use the infectious Oroqen dance in various cultural and artistic activities. On the one hand, it will please the minority nationalities; one the other hand, the travelers will be attracted by the special dance culture and the artistic atmosphere. Government should lead in the construction of a comprehensive cultural administrative system to realize the object to build up a cultural platform to gain economic success. It can also elevate our confidence to our national culture.

\section{B. Cultivation of the Awareness to Inherit Immaterial Culture Heritage}

The key to cultivate the awareness of the minority nationalities to inherit and develop immaterial culture heritage lies on the two points. First, we should improve the traditional national cultural educational system. The national art should be included in the educational system through compiling and using the textbooks of Oroqen language and songs to attract the people's attention to traditional national culture for better cultural heritage and development. Second, we should enhance the people's knowledge on immaterial cultural heritage to prevent misunderstandings. We should attract attention from all sectors of the society for benign development of cultural industry. 


\section{Popularization and Development of Dance Courses}

The government should develop various methods to inherit and develop Oroqen dance in the campus. Based on the heritage of the dances and culture of minor nationalities, we should not only open Oroqen dance courses in middle and primary schools but also in superior education institutions as an optional course. Moreover, we can encourage the students to participate various social activities on Oroqen dance on the platform of the schools, such as Oroqen dance contests. In this case, the students can know the actual situation on the front-line of this domain. At the same time, these activities can improve their practical ability. The students can also record the Oroqen dance and culture with informational and modernized approach to reserve such precious dance, cultural and artistic documents.

\section{CONCLUSION}

Folk dances of the minority nationalities are an artistic description of their people's daily life to praise their courage and diligence. With different expressive forms from ballet and sport dances, these folk dances pay more attention to present their culture, spirits and histories. Thus, they own particular artistic charms. China is a multinational country. At present, the cultural and artistic status of the minority nationalities are attracting more and more attention from the public in China. Based on its culture, the Oroqen dance is a new cultural and artistic form emerging under the era development and diversification of national culture. The thesis intends to analyze the cultural characteristics of the Oroqen dance in Heilongjiang River Basin, study the actual situation and measures of the heritage and development of dance culture and raise public concern on this issue.

\section{REFERENCES}

[1] Liping Tian. On the Development and Motivation of Minority Nationalities Dance [J], The Journal of Hebei Normal University: Humanities and Social Sciences, 2011,34(4):141-145.

[2] Meiwen Gong, On the Development of Chinese Minority Nationalities Dances - The Development of National Dances in Northwest China [J], Jiannan Literature: Classical Reading, 2012,(12):329.

[3] Liping Yu, The Exploration on the Education and Heritage of Dance Culture of Minority Nationalities from the Perspective of Discipline Construction $[\mathrm{J}]$, Journal of Taiyuan Urban Vocational College, 2014,(1):136-137,138.

[4] Lingling Zheng, On the Life Views in Traditional Sports and Dances of Minority Nationalities [J], Journal of Yunnan Nationalities University: Social Sciences, 2016,33(5):64-67.

[5] Yang Zhang, Research Review on Oroqen Dance Culture [J], Journal of Beijing Dance Academy, 2013.1.

[6] Shan Li \& Jianguo Zheng, Urban Square Culture and Heritage of Minority Nationalities Music and Dance - Taking the Development of Square Culture in Chengdu as an Example [J], Journal of Beijing Dance Academy, 2013,(4):214-217,9.

[7] Xuyuan Chen \& Hongli Yang, The Educative Choice in the Cultural Heritage of the Nations without Characters [M], Northeast Normal University Press, 2015.3. 